\title{
Effect of estrous detection strategy on pregnancy outcomes of lactating Holstein cows receiving artificial insemination and embryo transfer
}

\author{
Odinei Marques, ${ }^{1} \odot$ Anderson Veronese, ${ }^{1}$ Victória R. Merenda, ${ }^{1} \odot$ Rafael S. Bisinotto, ${ }^{1} \odot$ \\ and Ricardo C. Chebel ${ }^{1,2 *}$ (1) \\ ${ }^{1}$ Department of Large Animal Clinical Sciences, University of Florida, Gainesville 32611 \\ ${ }^{2}$ Department of Animal Sciences, Institute of Food and Agricultural Sciences, University of Florida, Gainesville 32611
}

\begin{abstract}
Objectives of the current experiment were to evaluate the effects on reproductive performance of adding an automated estrous detection (AED) device to the reproductive management of Holstein cows. In addition, we aimed to determine whether the AED device would equally influence the reproductive performance of cows receiving artificial insemination and those receiving embryo transfer. Cows $(\mathrm{n}=1,244)$ were observed daily for estrous detection by trained farm personnel with the aid of a tail head mounting device. Cows $(\mathrm{n}=641)$ enrolled in the AED treatment were fitted with a neck-mounted automated estrus detection device, and cows enrolled in the control (CTRL, $\mathrm{n}=$ 603 ) treatment were not fitted with the AED device. Cows not detected in estrus by $54 \pm 3$ DIM received 1 injection of $\mathrm{PGF}_{2 \alpha}$, and those not detected in estrus by $68 \pm 3$ DIM were enrolled in an ovulation synchronization protocol. The hazard of first service tended to be affected by treatment [CTRL: referent, AED: adjusted hazard ratio $(\mathrm{AHR})=1.11,95 \%$ confidence interval $(\mathrm{CI})=0.98,1.25]$, and we determined a tendency for the AED treatment to reduce the proportion of cows receiving the first service at fixed time $(39.7 \pm 5.7$ vs. $45.5 \pm 5.8 \%$ ). After the first service, high-producing cows enrolled in the AED treatment were more likely to be pregnant $(19.1 \pm 2.4$ vs. $31.8 \pm 3.0 \%)$, but no differences between the AED and CTRL treatments were observed among low-producing cows $(24.9 \pm 2.9$ vs. $24.7 \pm 2.9 \%)$. The hazard of second service was affected by treatment (CTRL: referent, AED: AHR $=1.22,95 \%$ $\mathrm{CI}=1.01,1.47)$, and the AED treatment reduced the proportion of cows receiving the second service at fixed time compared with the CTRL treatment $(15.7 \pm 2.2$ vs. $21.9 \pm 2.5 \%)$. After the second service, the AED treatment tended to increase the proportion of cows
\end{abstract}

Received November 11, 2019.

Accepted March 4, 2020.

*Corresponding author: rcchebel@ufl.edu pregnant $(31.0 \pm 3.0$ vs. $24.9 \pm 2.6 \%)$ and tended to reduce the proportion of cows that lost pregnancy between the first and second pregnancy exams $(9.7 \pm 3.3$ vs. $16.7 \pm 4.6 \%)$. The interaction between treatment and type of service did not affect percentage of cows pregnant and pregnancy loss to the first and second services. The hazard of pregnancy was affected by the interaction between treatment and milk yield, in that cows with above the median milk yield in the AED treatment became pregnant at a faster rate than CTRL cows, but no difference between treatments was observed among cows with milk yield below the median. Cows with above the median milk yield had shorter duration of estrus and were less likely to have activity peak at estrus $\geq 89(0=$ minimum, $100=$ maximum $)$. The current experiment suggests that AED devices may improve reproductive performance not only by increasing service rates but also by improving accuracy of estrous detection. According to the current experiment, high-producing cows may benefit most from the addition of AED devices to reproductive management. Key words: lactating Holstein cow, automated estrous detection, embryo transfer

\section{INTRODUCTION}

Reproductive performance is a key component of economic success in dairy herds, as it affects average milk yield, income over feed cost, and culling decisions (Giordano et al., 2012; Galvão et al., 2013). Despite the substantial advancements observed in the past 2 decades of programs for synchronization of ovulation and timed AI, refining estrous detection remains a major priority for dairy operations. Financial analyses using stochastic dynamic Monte Carlo simulation models indicated that improving efficiency of estrous detection from 40 to $60 \%$ and accuracy from 85 to $95 \%$ increased profit per cow by $\$ 83 /$ yr to $\$ 94 /$ yr when milk prices ranged from $\$ 0.33$ and $\$ 0.44 / \mathrm{kg}$ (Galvão et al., 2013). Improving efficiency and accuracy of estrous detection increases the profitability in dairy herds in which ovula- 
tion synchronization and timed AI are used (Giordano et al., 2012). Developing strategies to enhance estrous detection programs becomes exceedingly important given its widespread utilization. According to census data compiled by the US Department of Agriculture, 71 and $53 \%$ of surveyed dairy operations use estrous detection for first and subsequent services, respectively (USDA, 2016).

Notwithstanding its benefits, detection of estrus is often limited by environmental and animal-related factors. For instance, dairy cows housed on concrete flooring had less mounting activity and 4-h shorter estruses compared with counterparts housed on dirt surfaces (Britt et al., 1986; Vailes and Britt, 1990). The negative association between concrete flooring and estrous behavior is particularly relevant, given that in $83 \%$ of US dairy operations, cows are housed on concrete surfaces (USDA, 2016). Increases in temperature-humidity index (THI) and cows' incapacity to maintain core temperature have also been negatively associated with estrous behavior. Increases in THI have been associated with reduction in the diameter of ovarian follicles and subdued secondary signs of estrus (Schüller et al., 2017). Moreover, mean relative increase in activity associated with estrus events was greater for cows in THI $\leq 65$ compared with counterparts in estrus with THI $>65$ (Polsky et al., 2017). Elevated milk production observed in modern dairy breeds increases the challenges associated with estrous detection (Lopez et al., 2004; Madureira et al., 2015). High-producing Holstein cows $(\geq 39.5 \mathrm{~kg} / \mathrm{d})$ had smaller serum estradiol concentrations despite having larger ovulatory follicles, fewer standing events, lower total standing time, and reduced duration of estrus compared with low-producing counterparts $(<39.5 \mathrm{~kg} /$ d; Lopez et al., 2004). Such negative association between milk yield and estrous behavior is attributed to elevated DMI in support of lactation and the consequent increase in hepatic blood flow and rate of estradiol catabolism by the liver (Sangsritavong et al., 2002). It is noteworthy that Madureira et al. (2015), using an automated estrous detection (AED) device similar to that used in the current experiment, demonstrated that higher-producing cows had less intense and shorter estrus, despite not differing in estradiol concentration from lower-producing cows. Nonetheless, a higher activity peak was associated with greater plasma estradiol concentration.

The potential application of automated devices that track changes in physical activity associated with estrus for management of reproduction in cattle was first reported in the 1970s (Kiddy, 1977). Currently available AED devices monitor changes in activity and rumina- tion patterns compared with the individual's baseline values to estimate the onset of estrus and determine the ideal time for insemination (Fricke et al., 2014a). Automated estrous detection systems have become more accessible to dairy producers, but penetration among US dairy herds remains below 10\% (Denis-Robichaud et al., 2016; USDA, 2016). Expected changes in reproductive performance and profitability following implementation of AED devices is highly dependent on a herd's current performance. Therefore, it is critical to compare fertility outcomes in cows managed with specific AED devices with that of cows managed with other automated systems, timed AI programs, estrous detection based on mounting devices (i.e., tail paint or chalk and estrous-detection patches), and different combinations of these methods. Strategies to use AED devices for management of the first AI postpartum in dairy cows have been evaluated recently (Fricke et al., 2014b; Burnett et al., 2017; Denis-Robichaud et al., 2018). However, evaluation of reproductive efficiency in cows monitored with AED devices and exposed to timed AI protocols throughout lactation, compared with the use of mounting devices combined with timed AI, remains pending. Moreover, the effects of AED devices on fertility outcomes of lactating dairy cows receiving embryo transfer (ET) has not been assessed.

We hypothesized that incorporation of AED devices in the reproductive management of lactating Holstein cows would improve reproductive performance compared with cows managed exclusively with mounting devices. In addition, we hypothesized that the benefits from the AED devices would be more evident among cows receiving AI than among cows receiving ET. Objectives of the present experiment were to evaluate the effects of AED devices on hazard of first service, pregnancy per service, hazard of second service, and hazard of pregnancy in lactating Holstein cows managed using mounting devices and synchronization protocols and receiving $\mathrm{AI}$ and $\mathrm{ET}$.

\section{MATERIALS AND METHODS}

All procedures in this experiment were assessed and approved by the University of Florida (Gainesville) Institutional Animal Care and Use Committee (protocol \#201810496).

\section{Animals, Housing, and Management}

This experiment was conducted in a commercial dairy farm located in north central Florida, milking approximately 4,200 Holstein cows. Lactating cows were 
housed in tunnel-ventilated freestall barns equipped with high-pressure misters in the air inlet end of the barn. Soakers over the feed lane were activated when environmental temperatures exceeded $18^{\circ} \mathrm{C}$. During the experiment, cows were fed 4 times daily a TMR formulated to meet or exceed the nutritional requirements of lactating Holsteins weighing $\geq 680 \mathrm{~kg}$ of live BW and producing $45 \mathrm{~kg}$ of $3.5 \% \mathrm{FCM}$ (NRC, 2001). Cows were milked 3 times daily. The average rolling herd milk production was approximately $11,000 \mathrm{~kg}$ of milk/cow per year at the time of the experiment. Daily average temperature and dew point was collected from the Gainesville airport meteorological station, located approximately 40 miles east of the dairy. Daily THI was calculated using the average values for temperature and relative humidity. The percentage of days with THI $>68$ during the first 60 DIM was calculated for each cow. Cows were then divided as having spent either $<50 \%$ or $\geq 50 \%$ of days with average daily THI $>68$.

Information regarding parturition and incidence of disease postpartum were recorded by farm personnel and collected from the herd's management software (PCDART; Dairy Records Management Systems, Chapel Hill, NC). Calving difficulty was scored from 1 to $5(1=$ unassisted parturition; $2=$ minimal assistance; $3=$ moderate assistance; $4=$ severe assistance; $5=$ cesarean section or fetotomy), with dystocia defined as scores $>1$. Retention of fetal membranes was diagnosed based on visual inspection and vaginal palpation $24 \mathrm{~h}$ after calving. Stillbirth was defined as calves dead at delivery or that died within $24 \mathrm{~h}$ of delivery. Cows were evaluated for occurrence of metritis at 4, 6, 8, and 10 DIM, and metritis was defined as the presence of an enlarged uterus, as diagnosed by rectal palpation and associated with the presence of fetid, watery, brownish reddish vaginal discharge, independently of fever (Sheldon et al., 2006). Lameness was evaluated daily by herd managers via visual observation as cows were moved to and from the milking parlor. Herd managers were trained by veterinarians of the Food Animal Medicine Reproduction Service of the Department of Large Animal Clinical Sciences of the University of Florida according to Sprecher et al. (1997). As such, cows with locomotion scores 1 and 2 were considered normal, whereas cows with locomotion score 3 to 5 were considered lame. Mastitis was defined as abnormal milk (i.e., serous milk or presence of clots, blood, or pus) and positive California Mastitis Test (scores 1, 2, and 3; https://extension2.missouri.edu/g3653). Respiratory disease and indigestion were diagnosed by herd managers and were combined into "other diseases" for statistical analyses.

\section{Estrous Detection Methods and Treatments}

Visual detection of estrus was performed by trained farm personnel with the aid of tail head mounting devices (Estrotect; Rockway Inc., Spring Valley, WI). Daily from 0400 to $0600 \mathrm{~h}$, farm personnel walked all pens and visually detected estrus according to changes in behavior (standing to be mounted, mounting other cows, bellowing, increased nervousness and activity, walking fence line), which was confirmed by evaluation of the mounting device $(\geq 50 \%$ of the mounting device coating had been removed). In addition, twice daily, when cows exited the milking parlor, mounting devices were evaluated for removal of $\geq 50 \%$ of the coating, which was characterized as estrus and confirmed by secondary signs (swelling and reddening of the vulva, vaginal mucous discharge).

The AED devices comprised an accelerometer that measures activity and a microphone that records rumination events, mounted on a neck collar. Automated estrous detection devices were placed cranially on the left side of the neck. Both activity and rumination data were registered at 2 -h intervals, and information was uploaded to Data Flow II software (SCR Dairy Inc., Netanya, Israel). Such information was used for calculation of a heat index ranging from 0 (no estrus) to 100 (maximal estrus intensity), based on increased physical activity and decreased rumination frequency.

Cows assigned to the control treatment (CTRL; $\mathrm{n}=$ 831) were monitored for signs of estrus based on visual observation of standing behavior, aided by mounting devices. Cows assigned to the AED treatment $(\mathrm{n}=831)$ were monitored using AED devices (Heat Rumination Long Distance, SCR Dairy Inc.) in addition to visual observation aided by mounting devices as described for CTRL. Cows were enrolled in the experiment during two separate periods. During the first enrollment period, 663 cows were enrolled in the experiment (primiparous $=349$; multiparous $=314$ ). At $26 \pm 7$ DIM, weekly cohorts of cows were blocked by parity and average milk yield from calving to the day before enrollment. Within block, cows were allocated randomly to 1 of the 2 treatments $(\mathrm{CTRL}=331$, AED $=332)$. Cows enrolled in the first period calved between Oct. 16 and Dec. 16, 2016. During the second period, pregnant heifers $(n=499)$ that were part of another study (Chebel and Veronese, 2020) were used. These heifers received AED devices 2 wk before the expected calving date (actual interval $=13 \pm 9 \mathrm{~d}$ ) and were assigned to the AED treatment. Contemporaneous heifers that were not used in the study by Chebel and Veronese (2020) were matched with AED heifers based on calving date 
and were assigned to the CTRL treatment $(\mathrm{n}=500)$. Heifers enrolled in the second period calved between Dec. 15, 2016, and Dec. 1, 2017.

\section{Reproductive Management, Pregnancy Diagnosis, and Reproductive Data}

Cows were allowed a 48-d voluntary waiting period, after which those observed in estrus, as described for AED and CTRL treatments, received AI or ET. Artificial insemination was performed using frozen-thawed semen. Cows assigned to receive an embryo were examined via transrectal palpation of the ovaries at 5 to $9 \mathrm{~d}$ after detected estrus by the herd's veterinarian. Those cows determined to have a large corpus luteum in one of the ovaries (enlarged ovary $\geq 30 \mathrm{~mm}$ with a protruding corpus luteum) received either an in vivo (FSH-stimulated multiple ovulations) or an in vitroproduced embryo that had or had not been previously frozen. The distribution of cows according to type of service is depicted in Table 1. For statistical analyses, all embryo types were combined into a single group for comparison with AI. Cows that had not been detected in estrus by $54 \pm 3$ DIM received 1 injection of $\mathrm{PGF}_{2 \alpha}$. Cows not detected in estrus by $68 \pm 3$ DIM were enrolled in a G7G protocol (d -17 GnRH, d -10 GnRH, $\mathrm{d}-3 \mathrm{PGF}_{2 \alpha}, \mathrm{h}-16 \mathrm{GnRH}, \mathrm{d} 0$ timed AI; Dirandeh et al., 2015). Cows were monitored daily for signs of estrus after the first service as described for the AED and CTRL treatments, and those not observed in estrus before non-pregnancy diagnosis were enrolled in the G7G protocol.

Pregnancy diagnosis for cows enrolled in the first period was performed via transrectal ultrasonography (Easi-Scan; IMV Imaging North America Inc., Rochester, MN) at $33 \pm 3 \mathrm{~d}$ of presumptive gestation. For cows enrolled in the second period, pregnancy diagnosis was performed via rectal palpation of uterine contents at $42 \pm 3 \mathrm{~d}$ of presumptive gestation. Pregnant cows were re-examined at $95 \pm 3 \mathrm{~d}$ of gestation. For simplicity, pregnancy diagnosis will be defined as being performed on d 40 and 95 after AI or estrus associated with ET. Pregnancy per service (i.e., P/AI and P/ET) was calculated as the number of cows diagnosed pregnant on d 40 or 95 divided by the total number of cows serviced. Pregnancy loss was calculated as the number of cows that lost their pregnancies between d 40 and 95 divided by the number of cows pregnant on $\mathrm{d} 40$. Data regarding type of service (AI vs. ET), service trigger (detected estrus vs. synchronized ovulation), DIM at service, technician, sire, and dam of embryo were recorded for all services. Automated estrous detection devices were removed from cows diagnosed as pregnant on d 40 and from all remaining cows at 150 DIM, after which non-pregnant cows were right-censored. Cows defined as reproductive culls by farm personnel were censored from analyses of time to service and time to pregnancy accordingly.

\section{Estrous Characteristics According to Milk Yield}

Based on the intensity of changes in activity and rumination, an internal algorithm (DataFlow 2, SCR Dairy Inc.) calculated the heat index $(0=$ no estrus to $100=$ maximum estrus intensity). Heat index, activity peak $(0=$ no estrus, $100=$ maximum activity $)$, and rumination nadir (maximum difference in rumination time within a 2-h period during estrus compared with the average rumination within the same period in the previous 7 d) were recorded for all estrus events. Study personnel evaluated each activity graph individually and determined the time of onset (2-h period when the

Table 1. Distribution of type of service and type of embryo according to treatment and service number ${ }^{1}$

\begin{tabular}{|c|c|c|c|c|}
\hline \multirow[b]{2}{*}{ Variable, no. (\%) } & \multicolumn{2}{|c|}{ First service } & \multicolumn{2}{|c|}{ Second service } \\
\hline & CTRL & AED & CTRL & AED \\
\hline AI & $337(58.8)$ & $349(58.5)$ & $232(62.7)$ & $194(59.7)$ \\
\hline Embryo transfer & $236(41.2)$ & $249(41.6)$ & $138(37.3)$ & $131(40.3)$ \\
\hline \multicolumn{5}{|l|}{ Type of embryo ${ }^{2}$} \\
\hline MOV fresh & $64(27.1)$ & $75(30.1)$ & $46(33.3)$ & $47(35.9)$ \\
\hline MOV frozen-thawed & $15(6.4)$ & $13(5.2)$ & $10(7.3)$ & $10(7.6)$ \\
\hline IVP fresh & $90(38.1)$ & $94(37.8)$ & $45(32.6)$ & $44(33.6)$ \\
\hline IVP frozen-thawed & $67(28.4)$ & $67(26.9)$ & $37(26.8)$ & $30(22.9)$ \\
\hline
\end{tabular}

${ }^{1}$ Cows assigned to the control (CTRL) treatment were monitored for signs of estrus based on visual observation of standing behavior, aided by mounting devices (Estrotect; Rockway Inc., Spring Valley, WI). Cows assigned to the automated estrous detection (AED) treatment were monitored using AED devices (Heat Rumination Long Distance, SCR Dairy Inc., Netanya, Israel) in addition to visual observation aided by mounting devices, as described for CTRL.

${ }^{2} \mathrm{MOV}=$ multiple ovulation; IVP $=$ in vitro-produced. 
activity threshold was surpassed) and end (2-h period when the activity change was below the activity threshold) of estrus, and the duration of estrus was calculated (interval from onset to the end of estrus). Activity threshold was set at 3 -fold above the average activity for the same period in the previous $5 \mathrm{~d}$. Activity peak and heat index were skewed to the right. According to receiver operator characteristics, we determined that activity peak $\geq 89$ and heat index $\geq 89$ were criteria associated with greater likelihood of pregnancy at 95 $\mathrm{d}$ after service. Thus, cows were classified according to activity peak and heat index below or above 89 .

\section{Statistical Analyses}

The hypothesis of the current experiment was that the incorporation of an AED device in the reproductive management of lactating Holstein cows would improve their reproductive performance. A total of 570 cows per treatment were deemed necessary to detect a 7 -percentage-point difference in pregnancy to first service $(\alpha=$ $5 \%, \beta=20 \%$ ) when the percentage of cows enrolled in the CTRL treatment pregnant at $95 \mathrm{~d}$ after first service is $30 \%$. In addition, post hoc sample size calculations were conducted. To have $\leq 5 \%$ risk of type I and $\leq 20 \%$ risk of type II errors, 360 cows per treatment allowed us to detect a 9-percentage-point difference in pregnancy to $\mathrm{AI}$ between treatments $(\mathrm{CTRL}=35 \%$ vs. $\mathrm{AED}=$ $44 \%)$. Similarly, to prevent type I $(\alpha=5 \%)$ and type II $(\beta=20 \%)$ errors, a total of 250 cows per treatment allowed us to detect a 9-percentage-point difference in pregnancy per ET $(\mathrm{CTRL}=20 \%$ vs. $\mathrm{AED}=29 \%)$.

Cows and heifers that aborted $\geq 260 \mathrm{~d}$ gestation and were considered by farm personnel to have started a new lactation $(\mathrm{CTRL}=10, \mathrm{AED}=11)$, and cows selected as donors and subjected to protocols for multiple ovulation and embryo collection $(\mathrm{CTRL}=178, \mathrm{AED}=140)$ were removed from the experiment. From the remaining cows $(\mathrm{n}=1,323), 79$ left the herd or were deemed unfit to receive a service $\leq 47$ DIM by farm managers and were excluded from the experiment $(\mathrm{CTRL}=40, \mathrm{AED}$ $=39)$. Therefore, 1,244 cows $(\mathrm{CTRL}=603, \mathrm{AED}=$ 641) were available for statistical analyses. Descriptive statistics were calculated via either chi-squared (parity distribution across treatments, proportion of male calves, incidence of calving problems, uterine disease, lameness, mastitis, and other diseases) or ANOVA (average of milk yield from calving to 90 DIM) using the FREQ and MIXED procedures, respectively, of SAS (SAS/STAT version 9.4; SAS Institute Inc., Cary, NC).

Binary variables were analyzed through multivariable logistic regression using the LOGISTIC procedure of SAS. Hazard of first service, hazard of second service, and hazard of pregnancy were analyzed using Cox proportional hazard models in the PHREG procedure of SAS. For each of these analyses, cows were rightcensored at 90 DIM, $40 \mathrm{~d}$ from first service, and 150 DIM, respectively. When a variable had a $P \leq 0.10$ on the hazard of an event according to the multivariable analysis, the mean and median intervals to the event of interest were analyzed using the Wilcoxon test of equality in the LIFETEST procedure of SAS.

Fixed effects included in all models were period, treatment (AED vs. CTRL), parity (primiparous vs. multiparous), type of service (AI vs. ET), and breeding code (detected estrus vs. synchronized ovulation), and the interactions between treatment and parity, treatment and type of service, and treatment and breeding code. Using univariate analyses, the following variables were evaluated for their association with the outcomes: occurrence of calving problems (dystocia, twins, stillbirth), calf sex, occurrence of uterine diseases (retained fetal membranes, metritis, or both), occurrence of mastitis and lameness before breeding, occurrence of other diseases (yes vs. no), milk yield in the first 90 DIM (above vs. below median), and percentage of days with average THI $\geq 68$ (above vs. below median). Variables that, according to the univariate analyses, had $P \leq 0.10$ were offered to multivariable models. Variables with $P$ $>0.10$ were removed from the statistical models using a backward stepwise elimination method. Outcomes from the final multivariate models are presented as adjusted proportions $( \pm$ SEM) and adjusted hazard ratios (AHR) and 95\% confidence intervals (CI). Statistical significance was considered at $P \leq 0.05$, and $0.05<P$ $\leq 0.10$ was considered statistical tendency.

\section{RESULTS}

\section{Descriptive Statistics}

Descriptive statistics are presented in Table 2. Treatments did not differ $(P \geq 0.24)$ with regard to proportion of primiparous cows and proportion of cows that delivered male calves, incidences of calving problems, uterine disease, mastitis within 60 DIM, lameness within 60 DIM, and overall morbidity within 60 DIM, and average milk yield up to 90 DIM. Unexpectedly, the incidences of calving problems and mastitis within 60 DIM were different $(P \leq 0.05)$, whereas the proportion of cows delivering male calves and the incidence of lameness within 60 DIM tended $(P \leq 0.09)$ to differ between cows receiving AI or ET. Because of the reproductive strategy of the collaborating herd, the proportion of primiparous cows receiving AI was smaller than the proportion of primiparous cows receiving ET $(P<$ $0.01)$. 


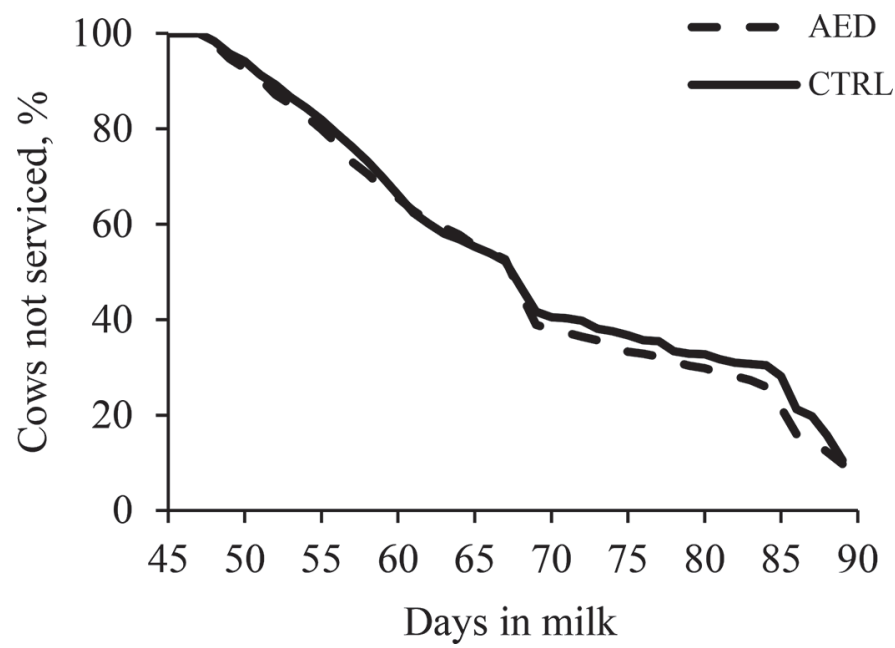

Figure 1. Effect of treatment on the rate at which cows received the first service. The median and mean $( \pm \mathrm{SEM})$ intervals from calving to first service were 68.0 and $69.0 \pm 0.6 \mathrm{~d}$, respectively, for CTRL and AED treatments (Wilcoxon test of equality $-P=0.26$ ). CTRL $=$ control; cows were monitored for signs of estrus based on visual observation of standing behavior aided by mounting devices (Estrotect; Rockway Inc., Spring Valley, WI). AED = automated estrous detection; cows were monitored using an AED device (Heat Rumination Long Distance; SCR Dairy Inc., Netanya, Israel) in addition to visual observation aided by mounting devices, as described for CTRL.

\section{Effects of Treatment and Type of Service on First-Service Outcomes}

The hazard of first service tended $(P=0.10)$ to be affected by treatment (CTRL: referent, AED: AHR = $1.11,95 \% \mathrm{CI}=0.98,1.25)$. The hazard of first service was lower $(P<0.01)$ for cows receiving AI $($ AHR $=$
$0.81,95 \%$ CI $=0.71,0.91)$ than for cows receiving ET (referent). The interaction between treatment and type of service did not $(P=0.39)$ affect the hazard of first service. The median interval from calving to first service was $68 \mathrm{~d}$ for both treatments and the mean $( \pm$ SEM) intervals were $69.0 \pm 0.6$ and $69.9 \pm 0.6 \mathrm{~d}$ for the AED and CTRL treatments, respectively (Figure 1). Among cows receiving AI for first service, the median and mean $( \pm \mathrm{SEM})$ intervals from calving to first service were 69.0 and $69.3 \pm 0.6 \mathrm{~d}$, respectively, whereas among cows receiving ET for first service, the median and mean $( \pm \mathrm{SEM})$ intervals from calving to first service were 66.0 and $67.7 \pm 0.5 \mathrm{~d}$, respectively. Exposure to $\geq 50 \%$ of days with average THI $\geq 68$ ( $P$ $=0.50)$ and milk yield $(P=0.80)$ did not affect the hazard of first service.

We detected a tendency $(P=0.08)$ for the AED treatment to reduce the proportion of cows receiving the first service at fixed time (Table 3$)$. Fewer $(P<$ 0.01) cows receiving ET received the first service at fixed time (Table 3), but no interaction between treatment and type of service was observed $(P=0.50)$. Cows that were exposed to $\geq 50 \%$ of days with average THI $\geq 68$ tended $(P=0.07)$ to be more likely to receive the first service at fixed time (46.2 \pm 0.1 vs. $39.0 \pm 0.1 \%)$.

The interaction between treatment and milk yield affected $(P \leq 0.03)$ pregnancy to first service at first and second exams. Among cows with below-median milk yield, treatment did not $(P \geq 0.98)$ affect pregnancy per service, but among cows with above-median milk yield, those enrolled in the AED treatment were $(P<$ $0.01)$ more likely to be pregnant at the first and second

Table 2. Descriptive statistics according to treatment and type of service ${ }^{1}$

\begin{tabular}{|c|c|c|c|c|c|c|c|}
\hline \multirow[b]{2}{*}{ Variable ( \pm SEM) } & \multicolumn{2}{|c|}{$\mathrm{AI}$} & \multicolumn{2}{|c|}{ Embryo transfer } & \multicolumn{3}{|c|}{$P$-value } \\
\hline & $\begin{array}{c}\text { CTRL } \\
(\mathrm{n}=337)\end{array}$ & $\begin{array}{c}\text { AED } \\
(\mathrm{n}=349)\end{array}$ & $\begin{array}{c}\text { CTRL } \\
(\mathrm{n}=236)\end{array}$ & $\begin{array}{c}\text { AED } \\
(\mathrm{n}=249)\end{array}$ & TRT & $\mathrm{TS}$ & $\mathrm{TRT} \times \mathrm{TS}$ \\
\hline Primiparous, \% & $72.1 \pm 2.4$ & $72.8 \pm 2.4$ & $80.9 \pm 2.6$ & $84.3 \pm 2.3$ & 0.36 & $<0.01$ & 0.49 \\
\hline Male calf, $\%$ & $53.7 \pm 3.5$ & $46.1 \pm 3.8^{\mathrm{A}}$ & $53.5 \pm 3.9$ & $59.4 \pm 4.2^{\mathrm{B}}$ & 0.83 & 0.09 & 0.08 \\
\hline Calving problems, $\%$ & $24.8 \pm 3.0$ & $24.9 \pm 3.2$ & $17.8 \pm 3.0$ & $18.2 \pm 3.2$ & 0.93 & 0.03 & 0.96 \\
\hline Uterine disease, $\%$ & $19.6 \pm 2.8$ & $15.8 \pm 2.7$ & $19.7 \pm 3.1$ & $20.2 \pm 3.3$ & 0.56 & 0.45 & 0.45 \\
\hline Mastitis within 60 DIM, \% & $5.3 \pm 1.6$ & $4.1 \pm 1.5$ & $1.5 \pm 0.9$ & $2.7 \pm 1.3$ & 0.69 & 0.05 & 0.31 \\
\hline Lameness within 60 DIM, \% & $5.7 \pm 1.6$ & $4.4 \pm 1.5$ & $1.7 \pm 1.0$ & $3.1 \pm 1.4$ & 0.68 & 0.07 & 0.29 \\
\hline Other diseases, ${ }^{2} \%$ & $1.5 \pm 0.8$ & $3.3 \pm 1.3$ & $0.6 \pm 0.6$ & $1.4 \pm 1.0$ & 0.24 & 0.21 & 0.99 \\
\hline Morbidity, ${ }^{3} \%$ & $36.7 \pm 3.4$ & $31.6 \pm 3.5$ & $29.3 \pm 3.5$ & $32.8 \pm 3.9$ & 0.84 & 0.39 & 0.24 \\
\hline Milk yield within 90 DIM, kg & $41.3 \pm 0.5$ & $41.2 \pm 0.5$ & $41.9 \pm 0.5$ & $41.4 \pm 0.6$ & 0.55 & 0.49 & 0.69 \\
\hline PctTHI68, $\%$ & $60.4 \pm 1.4$ & $61.4 \pm 1.4$ & $59.8 \pm 1.5$ & $64.7 \pm 1.6$ & 0.05 & 0.35 & 0.20 \\
\hline
\end{tabular}

$\overline{\mathrm{A}, \mathrm{B}}$ Within a row, values with different superscripts tended to differ $(0.05<P \leq 0.10)$.

${ }^{1}$ Cows assigned to the control (CTRL) treatment were monitored for signs of estrus based on visual observation of standing behavior aided by mounting devices (Estrotect; Rockway Inc., Spring Valley, WI). Cows assigned to the automated estrous detection (AED) treatment were monitored using AED devices (Heat Rumination Long Distance, SCR Dairy Inc., Netanya, Israel) in addition to visual observation aided by mounting devices, as described for CTRL. TRT = treatment. Type of service (TS): cows receiving AI or embryo transfer at first service postpartum. ${ }^{2}$ Respiratory disease and indigestion.

${ }^{3}$ At least one of the health disorders described.

${ }^{4}$ Percentage of cows that spent $\geq 50 \%$ of the first 60 DIM with average daily THI $\geq 68$. 
exams after the first service (Figure 2). The proportions of cows pregnant at the first and second pregnancy exams were $(P \leq 0.05)$ greater for those receiving AI compared with those receiving ET (Table 3 ). The interaction between treatment and type of service did not $(P=0.31)$ affect the proportion of cows pregnant to first and second pregnancy exams. Although treatment did not $(P=0.32)$ affect pregnancy loss, cows receiving ET tended $(P=0.07)$ to be more likely to lose a pregnancy between the first and second pregnancy exams (Table 3). The interaction between treatment and type of service did not $(P=0.80)$ affect pregnancy loss between the first and second pregnancy exams (Table 3 ).

\section{Effects of Treatment and Type of Service on Second-Service Outcomes}

The hazard of second service was $(P=0.04)$ affected by treatment (CTRL: referent, AED: AHR $=1.22,95 \%$ $\mathrm{CI}=1.01,1.47)$. The hazard of second service was $(P$ $<0.01)$ reduced for cows receiving $\mathrm{AI}(\mathrm{AHR}=0.78$, $95 \% \mathrm{CI}=0.64,0.94)$ compared with cows receiving ET (referent). The interaction between treatment and type of service did not $(P=0.71)$ affect the hazard of second service. The median and mean $( \pm \mathrm{SEM})$ intervals between the first and second services were 26 and 28.0 $\pm 0.5 \mathrm{~d}$ for the CTRL treatment, respectively, and 24 and $26.3 \pm 0.5 \mathrm{~d}$ for the AED treatment, respectively (Figure 3). Among cows receiving AI for second service, the median and mean $( \pm \mathrm{SEM})$ intervals from first to second services were 26 and $27.7 \pm 0.5$ d, respectively, whereas among cows receiving ET for second service, the median and mean $( \pm \mathrm{SEM})$ intervals from first to second services were 23 and $26.8 \pm 0.5 \mathrm{~d}$, respectively. Exposure to $\geq 50 \%$ of days with average THI $\geq 68$ ( $P$
$=0.47)$ and milk yield $(P=0.43)$ did not affect the hazard of second service.

The AED treatment reduced $(P=0.03)$ the proportion of cows receiving the second service at fixed time compared with the CTRL treatment (Table 3). Fewer $(P<0.01)$ cows receiving ET received the second service at fixed time (Table 3$)$, but no interaction $(P=$ 0.54 ) between treatment and type of service was observed regarding the proportion of cows receiving the second service at fixed time. Although treatment did not $(P=0.36)$ affect the proportion of cows pregnant at the first pregnancy exam, cows enrolled in the AED treatment tended $(P=0.07)$ to be more likely to be pregnant at the second pregnancy exam (Table 3 ). The proportion of cows that lost pregnancy between the first and second pregnancy exams tended $(P=0.09)$ to be reduced for cows enrolled in the AED treatment compared with cows enrolled in the CTRL treatment (Table 3). Type of service did not $(P \geq 0.13)$ affect the proportion of cows pregnant at first and second exams or the proportion of cows that lost pregnancy between the first and second exams. Similarly, the interaction between treatment and type of service did not $(P \geq$ 0.33 ) affect the proportion of cows pregnant at first and second exams or the proportion of cows that lost pregnancy between the first and second exams.

\section{Effects of Treatment and Milk Yield on Overall Reproductive Performance}

The interaction between treatment and milk yield within 90 DIM affected $(P<0.01)$ the hazard of pregnancy. Among cows with milk yield within 90 DIM above the median (Figure $4 \mathrm{~A}$ ), those enrolled in the AED treatment $[$ median $=100 \mathrm{~d}$, mean $( \pm \mathrm{SEM})=104.5$

Table 3. Effects of treatment and type of service on first and second service outcomes ${ }^{1}$

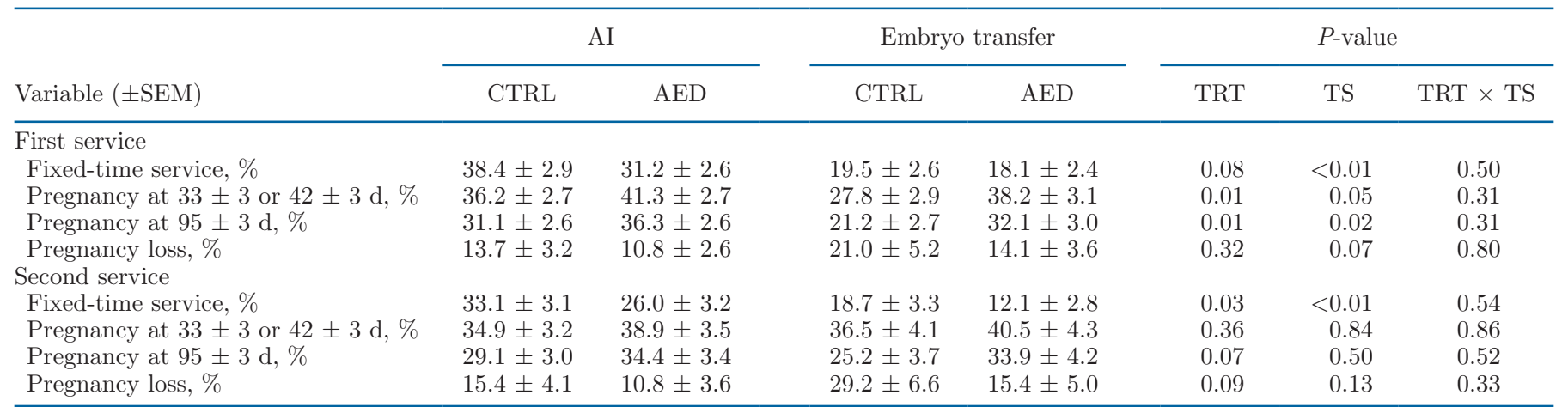

${ }^{1}$ Cows assigned to the control (CTRL) treatment were monitored for signs of estrus based on visual observation of standing behavior aided by mounting devices. Cows assigned to the automated estrous detection (AED) treatment were monitored using AED devices (Heat Rumination Long Distance, SCR Dairy Inc., Netanya, Israel) in addition to visual observation aided by mounting devices, as described for CTRL. TRT = treatment. Type of service (TS): cows receiving AI or embryo transfer at first service postpartum. 
$\pm 2.0 \mathrm{~d}]$ became pregnant at a faster rate compared with those enrolled in the CTRL treatment [median $=$ $141 \mathrm{~d}$, mean $( \pm \mathrm{SEM})=119.1 \pm 2.0 \mathrm{~d}]$. Conversely, no difference $(P=0.98)$ in rate of pregnancy was detected among cows with milk yield within 90 DIM below the median (Figure $4 \mathrm{~B})$. We did not $(P=0.54)$ detect a
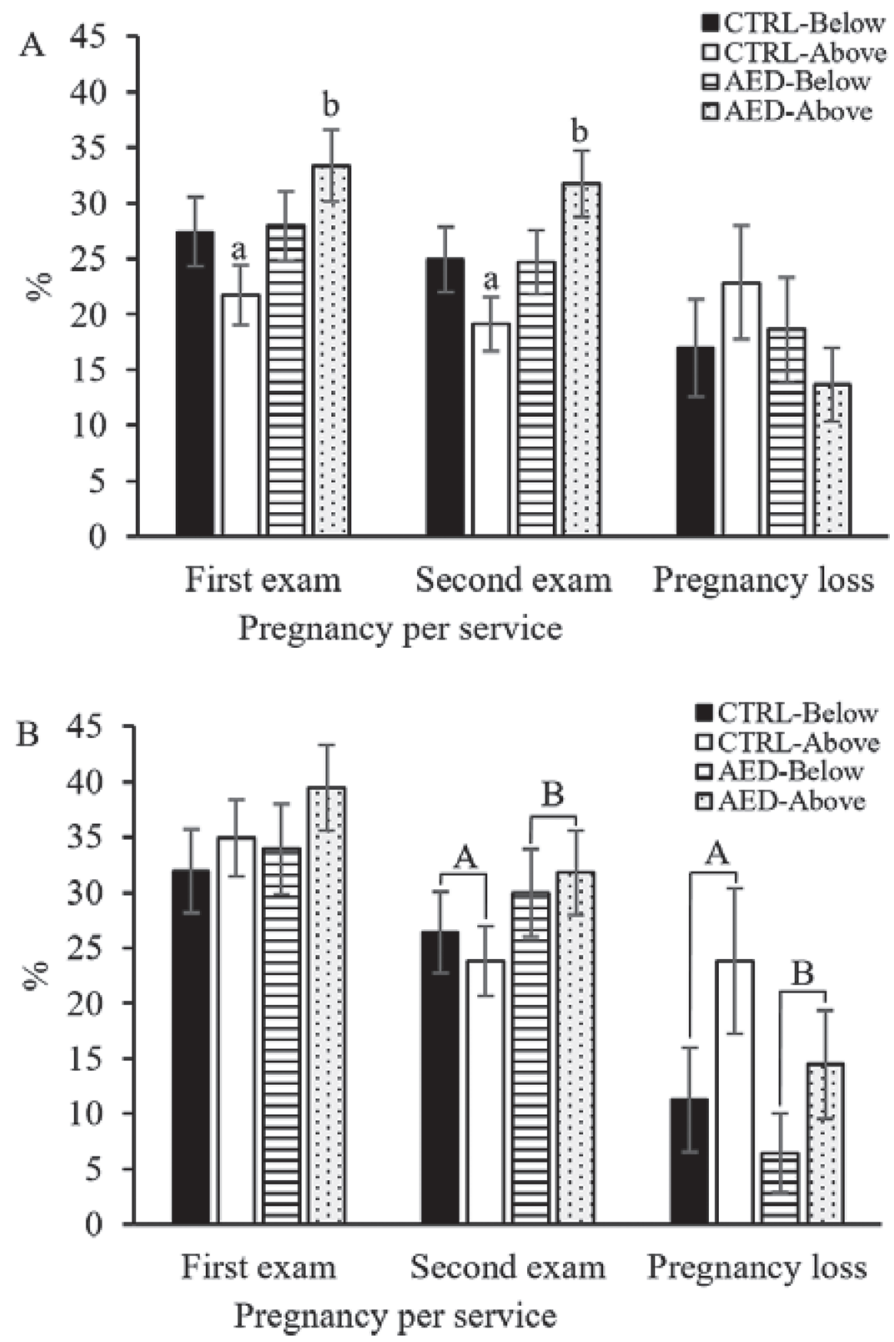

Figure 2. Effect of treatment on pregnancy at first $(33 \pm 3$ or $42 \pm$ $3 \mathrm{~d}$ of gestation) and second (95 $\pm 3 \mathrm{~d}$ of gestation) exams and pregnancy loss between the first and second exams to first (A) and second (B) services. First service: pregnancy per service - treatment $(P=$ $0.01)$, milk yield $(P \geq 0.84)$, and treatment $\times$ milk yield $(P \leq 0.03)$; and pregnancy loss - treatment $(P=0.32)$, milk yield $(P=1.00)$, and treatment $\times$ milk yield $(P=0.24) .{ }^{\mathrm{a}, \mathrm{b}} P \leq 0.05$. Second service: pregnancy per service - treatment $(P \leq 0.36)$, milk yield $(P>0.29)$, and treatment $\times$ milk yield $(P \geq 0.57)$; and pregnancy loss - treatment $(P$ $=0.09)$, milk yield $(P=0.02)$, and treatment $\times$ milk yield $(P=0.95)$. ${ }^{\mathrm{A}, \mathrm{B}} 0.05<P \leq 0.10$. CTRL $=$ control; cows were monitored for signs of estrus based on visual observation of standing behavior aided by mounting devices (Estrotect; Rockway Inc., Spring Valley, WI). AED $=$ automated estrous detection; cows were monitored using an AED device (Heat Rumination Long Distance; SCR Dairy Inc., Netanya, Israel) in addition to visual observation aided by mounting devices, as described for CTRL. Error bars represent SEM.

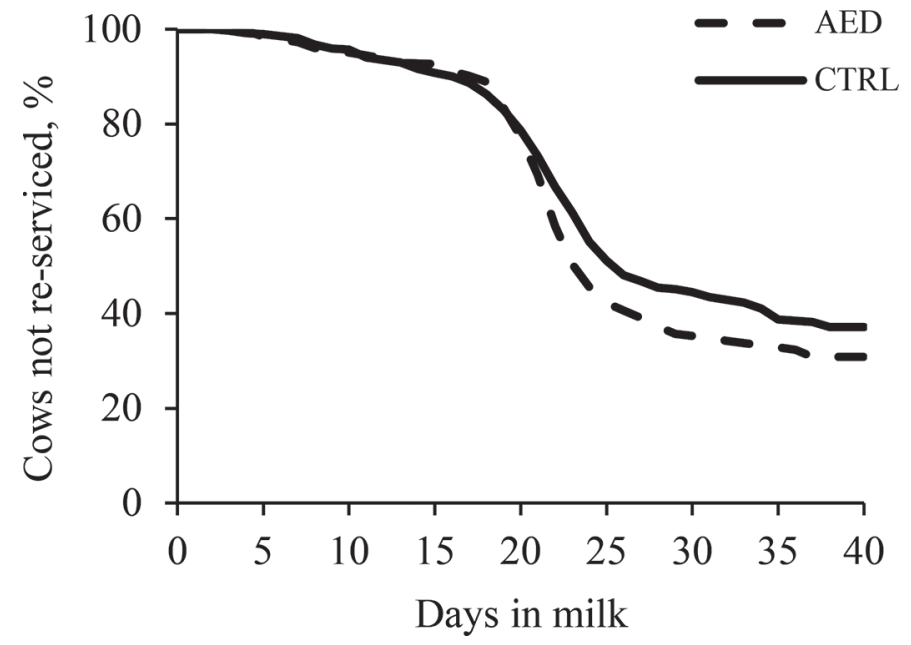

Figure 3. Effect of treatment on the rate at which cows received the second service. The median and mean $( \pm \mathrm{SEM})$ intervals between the first and second services were 26.0 and $28.0 \pm 0.5 \mathrm{~d}$, respectively, for the CTRL treatment and 24.0 and $26.3 \pm 0.5 \mathrm{~d}$, respectively, for the AED treatment (Wilcoxon test of equality $-P=0.04$ ). $\mathrm{CTRL}=$ control; cows were monitored for signs of estrus based on visual observation of standing behavior aided by mounting devices (Estrotect; Rockway Inc., Spring Valley, WI). AED = automated estrous detection; cows were monitored using an AED device (Heat Rumination Long Distance; SCR Dairy Inc., Netanya, Israel) in addition to visual observation aided by mounting devices, as described for CTRL.

difference in hazard of pregnancy according to percentage of days with average THI $\geq 68$.

\section{Estrous Characteristics According to Milk Yield}

Cows with milk yield above the median in the first 90 DIM had shorter estrus (below $=17.1 \pm 0.3$, above $=16.5 \pm 0.3 \mathrm{~h})$ and were less likely to have activity peak $\geq 89$ (below $=90.3 \pm 1.6$, above $=84.3 \pm 1.8 \%$ ) compared with cows with milk yield below the median in the first 90 DIM $(P \leq 0.05)$. We did not $(P \geq 0.45)$, however, detect an association between milk yield and rumination nadir at estrus (below $=-35.5 \pm 1.7$, above $=-36.6 \pm 1.7 \mathrm{~min})$ or the likelihood of having heat index $\geq 89$ at estrus (below $=67.3 \pm 2.8$, above $=66.0$ $\pm 2.6 \%)$. Exposure to $\geq 50 \%$ of days with average THI $\geq 68$ was not $(P \geq 0.16)$ associated with duration of estrus, rumination nadir, or likelihood of activity peak $\geq 89$ and heat index $\geq 89$.

\section{DISCUSSION}

Estrous expression is limited by environmental and animal-related factors that are largely intrinsic to the modern dairy industry, such as increased hepatic steroid catabolism associated with DMI to support elevated milk production, heat stress conditions, and concrete 
flooring (Britt et al., 1986; Vailes and Britt, 1990; Sangsritavong et al., 2002; Lopez et al., 2004). Developing strategies to improve accuracy and efficiency of estrous detection is critical, given its widespread ap-
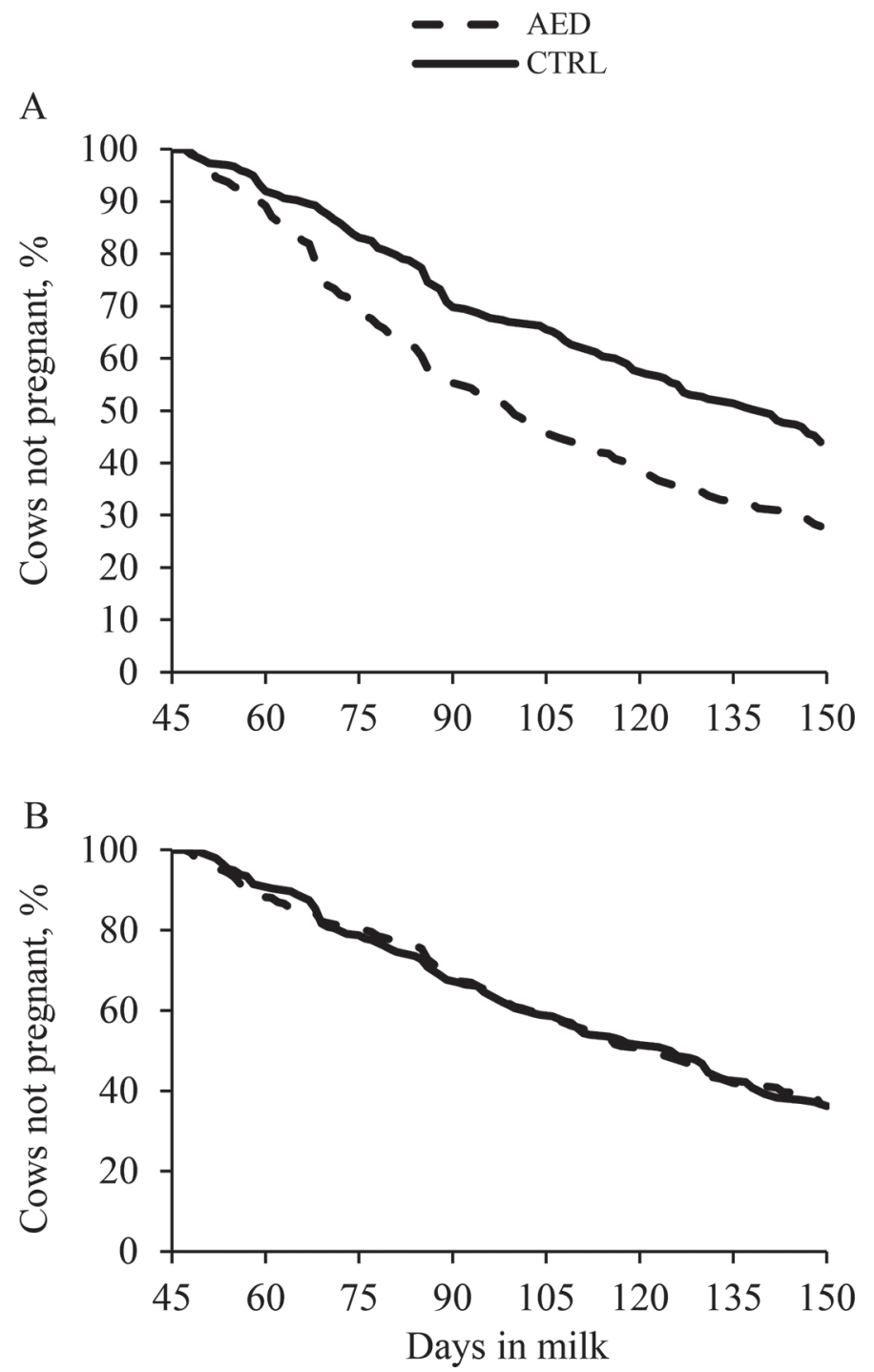

Figure 4. Effect of treatment on the rate at which cows became pregnant among cows with milk yield above (A) and below (B) the median. Among cows with milk yield above the median, the median and mean $( \pm \mathrm{SEM})$ interval from calving to pregnancy were as follows: CTRL treatment $=141$ and $119.1 \pm 2.0 \mathrm{~d}$, respectively; AED treatment $=100$ and $104.5 \pm 2.0 \mathrm{~d}$, respectively (Wilcoxon test of equality $-P<0.01)$. Among cows with milk yield below the median, the median and mean $( \pm$ SEM $)$ interval from calving to pregnancy were as follows: CTRL treatment $=126$ and $114.3 \pm 2.2 \mathrm{~d}$, respectively; AED treatment $=122$ and $113.8 \pm 2.2 \mathrm{~d}$, respectively (Wilcoxon test of equality $-P=0.92)$. CTRL $=$ control; cows were monitored for signs of estrus based on visual observation of standing behavior aided by mounting devices (Estrotect; Rockway Inc., Spring Valley, WI). AED $=$ automated estrous detection; cows were monitored using an AED device (Heat Rumination Long Distance; SCR Dairy Inc., Netanya, Israel) in addition to visual observation aided by mounting devices, as described for CTRL. plication in US dairy herds and its role in reproductive performance and overall herd profitability (Giordano et al., 2012; Galvão et al., 2013; USDA, 2016). In the current experiment, the addition of an AED device to the reproductive management of lactating dairy cows tended to increase the hazard of first service and increased the hazard of second service compared with visual and mounting device-aided detection of estrus. To our surprise, in the current experiment, milk yield and exposure to heat stress conditions were not associated with the hazard of first and second services, regardless of treatment. Improvements in efficiency of detection of estrus when using AED devices are highly dependent on the herd's efficiency of detection of estrus without AED devices. Thus, when considering whether the magnitude of change in hazard of services observed in the current experiment with the addition of the AED devices to the reproductive program would be observed in other situations, one must take into account the current hazard of services in each specific herd. Michaelis et al. (2014) demonstrated that, in a commercial German herd, the rate of estrus detection in the first $21 \mathrm{~d}$ after the end of the voluntary waiting period was not different between AED devices and visual observation, but AED devices increased estrous detection rates in the first 42 and $63 \mathrm{~d}$ after the end of the voluntary waiting period. We are unaware of other experiments that compared 2 estrous detection strategies for first and second postpartum services in the United States, but we expect that, in conditions similar to those observed in the collaborating herd, AED devices may prove beneficial for service rates of many herds. Several experiments have compared reproductive management using AED devices with strict fixed-time AI for first service. By design, the rate of first insemination is faster for cows subjected to insemination at detected estrus with AED, but, by a set DIM, all cows are inseminated as expected when fixed-time AI protocols are implemented (Fricke et al., 2014b; Denis-Robichaud et al., 2018).

The interaction between treatment and milk yield affected the proportion of cows pregnant to first service. Among cows with above-median milk yield, the proportion of cows enrolled in the AED treatment pregnant to first service was greater than cows enrolled in the CTRL treatment; among cows with milk yield below the median, however, no differences were observed between CTRL and AED treatments. Independent of milk yield, cows enrolled in the AED treatment tended to be more likely to be pregnant $95 \mathrm{~d}$ after the second service than cows enrolled in the CTRL treatment, because the former tended to be less likely to lose pregnancy between the first and second exams. Although it is difficult to explain how the use of AED devices would reduce pregnancy loss, the improvements 
in pregnancy to first and second service are likely a consequence of improvements in the accuracy of estrous detection and timely insemination, resulting in better synchrony between insemination and ovulation. In research conditions in which automated mounting devices (Valenza et al., 2012) or temporal progesterone changes (Nelson et al., 2017) were used as the gold standard for characterization of estrus, AED devices resulted in test characteristics (sensitivity, specificity, predicted value positive, predicted value negative) $\geq 85 \%$. Furthermore, Nelson et al. (2017) demonstrated that AED devices were more precise at determining ovulation, diagnosed by ultrasonography, than a complex visual estrous-detection scoring system. In the collaborating herd, farm personnel observed cows for signs of estrus (standing to be mounted, mounting other cows, bellowing, increased nervousness and activity, walking fence line, swelling and reddening of the vulva, and vaginal mucous discharge) with the aid of a mounting-detection device. One of the reasons for the experiment to be conducted in this herd, however, was the fact that concerns regarding accuracy of detection of estrus and the interval from onset of estrus to service had been raised by the herd manager and consulting veterinarians. In a previous experiment, we had determined that the accuracy of visual estrous detection in the collaborating herd, when using the AED device as the gold standard, was only $67 \%$ (Ricardo C. Chebel; personal communication). We conclude that in situations in which accuracy and timing of insemination based on visual detection of estrus are inappropriate, the addition of AED devices may prove beneficial to pregnancy per service.

We speculate that the AED treatment improved pregnancy to first service among cows with above-median milk yield because they were more likely to have estrus with reduced duration and intensity, which may affect the accuracy of visual detection of estrus. The greater DMI to support greater milk yield (Harrison et al., 1990) is believed to lead to increased hepatic blood flow and, consequently, greater catabolism of steroid hormones, including estradiol (Sangsritavong et al., 2002). Lopez et al. (2004) demonstrated that higherproducing cows were less likely to have long-duration $(\geq 8.7 \mathrm{~h})$ and high-intensity ( $\geq 0.6$ standing events $/ \mathrm{h}$ ) estrus compared with low-producing cows and were more likely to have short-duration $(<8.7 \mathrm{~h})$ and lowintensity $(<2.7$ standing events/h) estrus compared with low-producing cows. They also demonstrated that greater milk yield was associated with reduced estradiol peak at estrus (Lopez et al., 2004). Aungier et al. (2015) also demonstrated that estradiol concentration was positively associated with duration of standing estrus and estrous behaviors. It is noteworthy that Lopez et al. (2004) used AED devices based on mounting activity alone, whereas Aungier et al. (2015) used AED devices based on mounting activity and pedometry. Madureira et al. (2015), using similar AED devices to the ones used in the current experiment, demonstrated that high-producing cows had shorter and less-intense estrus than low-producing cows. Although Madureira et al. (2015) did not report an association between milk yield and estradiol concentration, cows with greater peak activity had greater estradiol concentration compared with cows with lower peak activity. Sartori et al. (2004) reported that, from luteolysis to ovulation, lactating dairy cows have larger ovulatory follicles than dairy heifers, but the former have reduced serum estradiol concentrations compared with heifers. We conclude that milk yield is generally associated with impaired estrous behavior, which is likely a consequence of changes in estradiol concentration.

A second hypothesis tested in the current experiment was that the difference in pregnancy per ET between treatments would be smaller than the difference in pregnancy per AI between treatments. This was hypothesized because all ET recipients had to be detected in estrus and had to have an enlarged ovary with a protruding CL on the day of the embryo transfer to receive an embryo. In fact, to our surprise, the magnitude of improvement in pregnancy per service due to the AED devices [(AED - CRTL)/CRTL] was greater for cows receiving ET (first service $=51.4 \%$, second service $=$ $34.5 \%$ ) than cows receiving AI (first service $=16.7 \%$, second service $=18.2 \%$ ). In addition, the magnitude of difference in pregnancy losses due to the AED devices [(AED - CRTL)/CRTL] were greater for cows receiving ET (second service $=47.3 \%$ ) than for cows receiving AI (second service $=29.9 \%$ ). Ferraz et al. (2016) demonstrated that asynchrony of the estrous cycle and embryo development was negatively associated with pregnancy per ET. Recipients receiving embryos on d 6 and 9 of the estrus cycle had 10\% lower pregnancy per ET than recipients receiving embryos on $\mathrm{d} 7$ and 8 (Ferraz et al., 2016). This leads us to speculate that the improved estrus-detection accuracy resulting from the use of AED devices may have improved the synchrony of the estrus cycle of recipients and the stage of development of embryos, which may have led to greater improvements in pregnancy per service.

The lack of effect of the interaction between treatment and milk yield on pregnancy to second service may be a consequence of the inherent differences in timing of first and second services. Caloric intake and energy balance increase rapidly from wk 3 postpartum to wk 13 postpartum, after which a plateau is observed (Maltz et al., 2013). We speculate that differences in caloric intake between high- and low-producing cows may have been more dramatic earlier postpartum, be- 
fore the first service, which could have had a greater influence on the cows' ability to display strong estrus, impairing the accuracy of visual estrous detection.

The positive effect of the AED treatment on hazard of pregnancy was observed only among high-producing cows. This may be explained by the improvements in hazard of first and second services due to the addition of the AED devices to the reproductive program and improvements in pregnancy per service. Similar to our findings, Michaelis et al. (2014) demonstrated that the use of AED devices increased the percentage of cows pregnant at 200 DIM compared with visual observation, despite having small effects on the rate of insemination. Several experiments have compared the reproductive performance of cows that, for the first service, were managed either with $100 \%$ fixed-time AI or with AED devices and fixed-time AI. In most of these experiments, management of the services subsequent to the first service were not different. Although some reports suggest that management of first service with AED devices improves hazard of pregnancy (Stevenson et al., 2014), others have detected no differences (Fricke et al., 2014b). Denis-Robichaud et al. (2018), in fact, detected an interaction between herd and reproductive protocol, suggesting that, in herds with optimum compliance with schedule of injections, the use of $100 \%$ fixed-time AI for first service may be advantageous. From the current experiment, we conclude that the use of AED devices up to 150 DIM improves the hazard of pregnancy of high-producing cows compared with visual detection of estrus, by improving hazard of services, particularly the second service, and pregnancy per service.

\section{CONCLUSIONS}

The efficient and accurate visual detection of estrus by observation of primary and secondary signs is often impaired because of animal- and management-related factors. In the current experiment, the use of an AED device in addition to visual detection of estrus proved to be minimally beneficial for hazard of first and second services. Nonetheless, significant benefits to pregnancy per service and, to our surprise, pregnancy loss were observed when the AED device was used to aid detection of estrus. Contrary to our secondary hypothesis, the benefits of AED devices were more evident among cows receiving ET than among cows receiving AI. We speculate that use of AED devices improved the synchrony between stage of the estrous cycle of the recipient and the transferred embryo and, hence, improved fertility. We conclude that, in the collaborating herd, minimal differences in hazard of services between the AED and CTRL treatments were a consequence of the inaccurate classification of estrus based solely on visual detection, resulting in service of cows that were not in estrus, and the reduced pregnancy per service. Therefore, when determining whether an AED device may benefit the reproductive performance of a herd, one should take into account the efficiency and accuracy of the estrous-detection strategy currently used by the herd in question.

\section{ACKNOWLEDGMENTS}

The authors thank the owners and staff of North Florida Holsteins dairy (Bell, FL) for their support and collaboration. The authors have not stated any conflicts of interest.

\section{REFERENCES}

Aungier, S. P. M., J. F. Roche, P. Duffy, S. Scully, and M. A. Crowe. 2015. The relationship between activity clusters detected by an automatic activity monitor and endocrine changes during the periestrous period in lactating dairy cows. J. Dairy Sci. 98:1666-1684. https://doi.org/10.3168/jds.2013-7405.

Britt, J. H., R. G. Scott, J. D. Armstrong, and M. D. Whitacre. 1986. Determinants of estrous behavior in lactating Holstein cows. J. Dairy Sci. 69:2195-2202. https://doi.org/10.3168/jds.S0022 $-0302(86) 80653-1$.

Burnett, T. A., A. M. L. Madureira, B. F. Silper, A. C. C. Fernandes, and R. L. A. Cerri. 2017. Integrating an automated activity monitor into an artificial insemination program and the associated risk factors affecting reproductive performance of dairy cows. J. Dairy Sci. 100:5005-5018. https://doi.org/10.3168/jds.2016-12246.

Chebel, R. C., and A. Veronese. 2020. Associations between genomic merit for daughter pregnancy rate of Holstein cows and metabolites postpartum and estrus characteristics. J. Dairy Sci. 103. https://doi.org/10.3168/jds.2020-18207.

Denis-Robichaud, J., R. L. A. Cerri, A. Jones-Bitton, and S. J. LeBlanc. 2016. Survey of reproduction management on Canadian dairy farms. J. Dairy Sci. 99:9339-9351. https://doi.org/10.3168/jds .2016-11445.

Denis-Robichaud, J., R. L. A. Cerri, A. Jones-Bitton, and S. J. LeBlanc. 2018. Performance of automated activity monitoring systems used in combination with timed artificial insemination compared to timed artificial insemination only in early lactation in dairy cows. J. Dairy Sci. 101:624-636. https://doi.org/10.3168/jds.2016 -12256 .

Dirandeh, E., A. R. Roodbari, M. Gholizadeh, H. Deldar, R. Masoumi, M. Kazemifard, and M. G. Colazo. 2015. Administration of prostaglandin F2 $\alpha 14 \mathrm{~d}$ before initiating a G6G or a G7G timed artificial insemination protocol increased circulating progesterone prior to artificial insemination and reduced pregnancy loss in multiparous Holstein cows. J. Dairy Sci. 98:5414-5421. https://doi .org/10.3168/jds.2015-9417.

Ferraz, P. A., C. Burnley, J. Karanja, A. Viera-Neto, J. E. Santos, R. C. Chebel, and K. N. Galvão. 2016. Factors affecting the success of a large embryo transfer program in Holstein cattle in a commercial herd in the southeast region of the United States. Theriogenology 86:1834-1841. https://doi.org/10.1016/j.theriogenology.2016 .05 .032 .

Fricke, P. M., P. D. Carvalho, J. O. Giordano, A. Valenza, G. Lopes Jr., and M. C. Amundson. 2014a. Expression and detection of estrus in dairy cows: The role of new technologies. Animal 8(s1):134143. https://doi.org/10.1017/S1751731114000299.

Fricke, P. M., J. O. Giordano, A. Valenza, G. Lopes Jr., M. C. Amundson, and P. D. Carvalho. 2014b. Reproductive performance of lactating dairy cows managed for first service using timed artificial 
insemination with or without detection of estrus using an activitymonitoring system. J. Dairy Sci. 97:2771-2781. https://doi.org/10 $.3168 / \mathrm{jds} .2013-7366$.

Galvão, K. N., P. Federico, A. De Vries, and G. M. Schuenemann. 2013. Economic comparison of reproductive programs for dairy herds using estrus detection, timed artificial insemination, or a combination. J. Dairy Sci. 96:2681-2693. https://doi.org/10.3168/ jds.2012-5982.

Giordano, J. O., A. S. Kalantari, P. M. Fricke, M. C. Wiltbank, and V. E. Cabrera. 2012. A daily herd Markov-chain model to study the reproductive and economic impact of reproductive programs combining timed artificial insemination and estrus detection. J. Dairy Sci. 95:5442-5460. https://doi.org/10.3168/jds.2011-4972.

Harrison, R. O., S. P. Ford, J. W. Young, A. J. Conley, and A. E. Freeman. 1990. Increased milk production versus reproductive and energy status of high producing dairy cows. J. Dairy Sci. 73:27492758. https://doi.org/10.3168/jds.S0022-0302(90)78960-6.

Kiddy, C. A. 1977. Variation in physical activity as an indication of estrus in dairy cows. J. Dairy Sci. 60:235-243. https://doi.org/10 .3168/jds.S0022-0302(77)83859-9.

Lopez, H., L. D. Satter, and M. C. Wiltbank. 2004. Relationship between level of milk production and estrous behavior of lactating dairy cows. Anim. Reprod. Sci. 81:209-223. https://doi.org/10 .1016/j.anireprosci.2003.10.009.

Madureira, A. M., B. F. Silper, T. A. Burnett, L. Polsky, L. H. Cruppe, D. M. Veira, J. L. Vasconcelos, and R. L. Cerri. 2015. Factors affecting expression of estrus measured by activity monitors and conception risk of lactating dairy cows. J. Dairy Sci. 98:7003-7014. https://doi.org/10.3168/jds.2015-9672.

Maltz, E., L. F. Barbosa, P. Bueno, L. Scagion, K. Kaniyamattam, L. F. Greco, A. De Vries, and J. E. Santos. 2013. Effect of feeding according to energy balance on performance, nutrient excretion, and feeding behavior of early lactation dairy cows. J. Dairy Sci. 96:5249-5266. https://doi.org/10.3168/jds.2013-6549.

Michaelis, I., O. Burfeind, and W. Heuwieser. 2014. Evaluation of oestrous detection in dairy cattle comparing an automated activity monitoring system to visual observation. Reprod. Domest. Anim. 49:621-628. https://doi.org/10.1111/rda.12337.

Nelson, S. T., C. S. Haadem, A. Nødtvedt, A. Hessle, and A. D. Martin. 2017. Automated activity monitoring and visual observation of estrus in a herd of loose housed Hereford cattle: Diagnostic accuracy and time to ovulation. Theriogenology 87:205-211. https:/ /doi.org/10.1016/j.theriogenology.2016.08.025.

NRC. 2001. Nutrient Requirements of Dairy Cattle. 7th rev. ed. Natl. Acad. Press, Washington, DC.

Polsky, L. B., A. M. L. Madureira, E. L. D. Filho, S. Soriano, A. F. Sica, J. L. M. Vasconcelos, and R. L. A. Cerri. 2017. Association between ambient temperature and humidity, vaginal temperature, and automatic activity monitoring on induced estrus in lactat- ing cows. J. Dairy Sci. 100:8590-8601. https://doi.org/10.3168/ jds.2017-12656.

Sangsritavong, S., D. K. Combs, R. Sartori, L. E. Armentano, and M. C. Wiltbank. 2002. High feed intake increases liver blood flow and metabolism of progesterone and estradiol-17 $\beta$ in dairy cattle. J. Dairy Sci. 85:2831-2842. https://doi.org/10.3168/jds.S0022 $-0302(02) 74370-1$

Sartori, R., J. M. Haughian, R. D. Shaver, G. J. M. Rosa, and M. C. Wiltbank. 2004. Comparison of ovarian function and circulating steroids in estrous cycles of Holstein heifers and lactating cows. J. Dairy Sci. 87:905-920. https://doi.org/10.3168/jds.S0022 -0302(04)73235-X.

Schüller, L. K., I. Michaelis, and W. Heuwieser. 2017. Impact of heat stress on estrus expression and follicle size in estrus under field conditions in dairy cows. Theriogenology 102:48-53. https://doi .org/10.1016/j.theriogenology.2017.07.004.

Sheldon, I. M., G. S. Lewis, S. LeBlanc, and R. O. Gilbert. 2006. Defining postpartum uterine disease in cattle. Theriogenology 65:1516-1530. https://doi.org/10.1016/j.theriogenology.2005.08 .021 .

Sprecher, D. J., D. E. Hostetler, and J. B. Kaneene. 1997. A lameness scoring system that uses posture and gait to predict dairy cattle reproductive performance. Theriogenology 47:1179-1187. https:// doi.org/10.1016/s0093-691x(97)00098-8.

Stevenson, J. S., S. L. Hill, R. L. Nebel, and J. M. DeJarnette. 2014. Ovulation timing and conception risk after automated activity monitoring in lactating dairy cows. J. Dairy Sci. 97:4296-4308. https://doi.org/10.3168/jds.2013-7873.

USDA. 2016. Dairy 2014: Dairy Cattle Management Practices in the United States. USDA-APHIS-VS-CEAH-NAHMS, Fort Collins, $\mathrm{CO}$.

Vailes, L. D., and J. H. Britt. 1990. Influence of footing surface on mounting and other sexual behaviors of estrual Holstein cows. J Anim. Sci. 68:2333-2339. https://doi.org/10.2527/1990.6882333x.

Valenza, A., J. O. Giordano, G. Lopes Jr., L. Vincenti, M. C. Amundson, and P. M. Fricke. 2012. Assessment of an accelerometer system for detection of estrus and treatment with gonadotropin-releasing hormone at the time of insemination in lactating dairy cows. J. Dairy Sci. 95:7115-7127. https://doi.org/10.3168/jds.2012-5639.

\section{ORCIDS}

Odinei Marques (๑ https://orcid.org/0000-0002-9951-9659 Victória R. Merenda (๑) https://orcid.org/0000-0002-4745-9762

Rafael S. Bisinotto $\odot$ https://orcid.org/0000-0001-6144-2919

Ricardo C. Chebel ๑ https://orcid.org/0000-0002-9700-8089 